\title{
Implement a Four-Step Process to Achieve 360-Degree E-learning Accessibility
}

\author{
Dr. Cynthia Schreihans \\ Management Department Coordinator \\ Jack H. Brown College of Business and Public Administration \\ CSUSB-Palm Desert Campus \\ 37500 Cook Street, Palm Desert, California-92211 \\ USA
}

\begin{abstract}
For higher education's e-learning (online and hybrid) courses, this paper shares a four-step pedagogical process titled, "360-Degree Accessibility." Process implementation helps to improve success for disabled students; specifically, students with visual and auditory impairments that require the use of assisted technology devices for course comprehension. An effective e-learning environment with equal opportunity and reasonable accommodation is promoted. The steps expand upon instructor-based accessibility guidelines so that, all class participants learn and practice accessibility standards, inside and outside of a classroom. Accessibility knowledge gained provides enhancements to students' social awareness and social responsibility. The differences between compliant and noncompliant practices are explained. Assisted technology, accessibility, discriminatory practices along with, elearning parameters is defined. Examples of syllabus passages and student lesson plans are provided. Process success is recognized within a pilot study. Final comments encourage the instructional use of 360-Degree Accessibility within higher education's e-learning courses.
\end{abstract}

Keywords: accessibility, e-learning, online, hybrid, disabled students, visual impairment, auditory impairment, higher education

\section{Introduction and Purpose}

Due to exclusion, "inaccessible" depictse-learning (online and hybrid) course content which prevents access for some or all disabled students and is therefore, considered noncompliant. Exclusion constitutes discrimination. In society and education, discrimination is against the law (Department of Education, 2008). "Accessible" course content is inclusive and compliant for all students. Discrimination is not present. Within higher education's e-learning environments, the development of accessible, compliant, course materials are vital, because equal opportunity includes reasonable accommodation. All students have a right to learn at their full capacity (Bakia, Shear, Toyama, \& Lasseter,2012).

As important as accessible, complaint e-learning course content is, sadly, it's a fact; nationwide, many colleges and universities have been faced with discrimination lawsuits due to inaccessible, noncompliant, e-learning courses (University of Washington, 2018).Legal debates which stem from discrimination need to be alleviated. This paper's Four-Step Process titled, "360-Degree Accessibility” can help to educate the whole, equally.

Knowledge of, and practice of, accessibility guidelines allows each learner to better understand the needs of disabled populations. These skills naturally instill equal opportunity with reasonable accommodation, in education, in citizenship, and in professional endeavors. Accessibility practices become second-nature. Spillovers enrich students' social awareness and social responsibility.

The CEO of Scandinavian Airlines is quoted as stating, "An individual without information cannot take responsibility; an individual who is given information cannot help but take responsibility" (Carlzon, 1987). Also, "The technology environment of today's ... schools should match the tools and approaches of the work and civic life that students will encounter after graduation" (National Education Association, 2018). Knowledge shared, isn't shared knowledge, if shared knowledge, isn't accessible for all learners. With four steps, inaccessibility gaps can be bridged. Turn noncompliante-learning into compliant e-learning.

\section{E-learning and Assisted Technologies}

Courses classified as e-learning are housed within electronic platforms such as Blackboard, Moodle, WebCT, Canvas and so forth. All these platforms organize instructor created course curriculums to present to students. To gain platform access and attend classes, students' logon via the Internet (Blackboard, 2018). E-learning classrooms are commonly classified as either, "Online" or "Hybrid." 
Online compositions fill a gap for those unable to attend a traditional face-to-face, synchronous learning, "brick and mortar" classroom. Typically, an online course structure is asynchronous and does not require the students' or the instructor's physical classroom presence (Crawford, Barker, \& Seyam, 2014). Blended instruction defines a hybrid course. Usually, this course structure is a face-to-face classroom where sessions are supplemented and/or substituted with online sessions. Hybrid is a middle-ground to e-learning (Graham, Allen, \& Ure, 2005; Watson, 2008).

Virtual-based, e-learning courses continue to grow in popularity and are an integral part of today's higher educational options (Allen \& Seaman, 2014). Electronically these platforms provide many perks; however, these same platforms can provide handicaps. Not all capabilities within these platforms are inherently accessible and/or compliant for disabled students; more verifiable, students with visual and/or auditory impairments (Fichten, Asuncion, Barile, Ferraro, \& Wolforth, 2009). Overcoming e-learning obstacles is a dominate concern (University of Washington, 2018). Students must be able to, when needed, use common assisted technology devices:

- Text-to-Speech. Reads aloud, what is on the computer screen.

- Optical Character Recognition. Converts/scans hardcopy print to electronic text.

- Refreshable Braille Display. Provides electronic screen interactions for visual impairments.

- Braille Monitor. Spells out text with raised dots; a finger traces over dots to read characters.

- Screen Magnifier. Anchors to a computer screen to enlarge text and/or image.

Technology devices stated are not needed by non-disabled students (National Institutes of Health, 2018)

\section{Disability, Accessibility and Discrimination}

Disability is tagged in social practice rather than tagged within a person. The impact of society and its decisions many times will cause a disability to indeed be, a disability (Finkelstien, 1980). For example, a student may need wheelchair assistance to provide him or her mobility to attend a traditional, on-campus classroom. If the educational institution does not provide a wheelchair ramp into the classroom, then the student's disability is indeed, a disability. In similarity, online courses without 360-Degree Accessibility would restrict some disabled populations. Limitations cause a disability to be indeed, a disability.

The formal definition of "accessible" used by the Office of Civil Rights and the U.S. Department of Education regarding inaccessible information technology follows:

"Accessible" means a person with a disability is afforded the opportunity to acquire the same information, engage in the same interactions, and enjoy the same services as a person without a disability in an equally effective and equally integrated manner, with substantially equivalent ease of use. The person with a disability must be able to obtain the information as fully, equally, and independently as a person without a disability (Educause, 2018).

The United States, Federal Government clarifies lack of reasonable accommodation:

"Accommodations" are adaptations made for specific individuals when a product or service is not accessible, such as providing captions on a video only when a specific student who is deaf requests them rather than including them in the original product design. Among the most common accommodations made for students with disabilities in online courses are the addition of captions to videos for students who are deaf and the remediation of documents to make them accessible to students who are blind and use screen readers to access content or who have dyslexia and other learning disabilities that make reading easier when they can see printed words and listen to them spoken at the same time. Proactively developing, procuring, and using accessible software, websites, videos, documents, and other IT reduces the need for accommodations (2018).

Different legislations which promote online, educational accessibility with reasonable accommodation are signed into law; for example, Title VII of the 1963 Civil Rights Act and Section 504 of the Rehabilitation Act of 1973. These statutes help protect students with disabilities from discrimination with assurance that, accessible education is provided to the same extent it is provided to nondisabled students (U.S. Department of Education, 2010; U.S. Department of Justice, 2010).

Complaints about these laws include retrofitted criteria (Ellis \& Kent, 2011). The goal for equal access is to make course content accessible from the start (Ingeno, 2013). Disabled students can perceive a negative impact on their ability to succeed in online courses due to discrimination (Roberts, Crittenden, \& Crittenden, 2011), regardless of current laws. The Four-Step, 360-Dregree Accessibility process promotes preplanned instruction which, requires students learn accessibility guidelines during the first week of class. Students recognize upfront, course-related, reasonable accommodation is present and therefore, preconceived, negative perceptions toward education shift positive. Educational quality is not sacrificed. 


\section{Four-Step Process and Implementation}

A lesson's value and its growth opportunity are based in the student's interpretation (Ames \& Archer, 1988). For instance, students who learn about accessible, compliant applications must distinguish skill merit for class purposes and futures endeavors. According to Gee (2008), it's essential to make the educational experience valuable and avoid Dewey's coined trap, "miseducative" (1938). Lessons should include four distinctive elements; (1) present a specific goal, (2) provide opportunity for interpreting the experience, (3) provide the student with feedback, and (4) allow students to incorporate social interactions into the educational experience.

The Four-Step Process, 360-Degree Accessibility includes elements of student interpretation along with, the support of Dewey's 1938, four distinctive elements. (See Figure 1: Flowchart, Four Step, 360-Degree Accessibility.) Platformbased course materials can be presented in any instructional preference (e.g., video, PowerPoint, hyperlink, etc.). Elaboration and customization are encouraged. Process steps are flexible enough to meet each instructor's teaching style. The samples provided below, should not be viewed as "one size fits all." Modifications are acceptable:

\section{1}

\section{Step I}

Syllabus Description. Require Accessibility Standards. (Dewey's (1938), Element 1: Present a specific goal.)Disclose accessibility expectations upfront (Picard, 2015). Document notations:

1. Students enrolled in this online/hybrid class may possess disabilities such as visual or auditory impairments and therefore, require assisted technology devices to see, hear, and read course materials.

2.Equal opportunity with reasonable accommodation for all class participants is sought; thus, compliant, assessible, nondiscriminatory communication is also required by all.

3. Accessibility guidelines and compliance concepts go beyond the assigned textbook's content; in addition, coursedemonstrated accessibility skills can be applied to all future "real-world" endeavors.

4. Class policies uphold anonymity as disabled students may prefer nondisclosure of limitations (May \& Stone, 2010); however, students are not required to anticipate or be made aware of each learner's individual needs.

\section{2}

\section{Step II}

Basic Techniques. What is and what is not, accessible. (Dewey's (1938) Element 2: Provide opportunity for interpreting the experience.)Course Methods:

1.In this course's digital space, flexibility of text (i.e., font types, font sizes, graphic highlights, color schemes, etc.) along with, platform features are not automatically accessible; as such, texts that are not flexible for users to modify them, exclude some users from communication(Sushil, Oswal $1 \&$ Meloncan, 2014). Two examples are; (1)Visually impaired students may not be able to read a PDF with scanned-in versions of original paper documents, and (2) Auditory impaired students may not be able to discuss an online video without closed captioning or without an associated transcript (Burgstahler, Corrigan\& McCarter, 2004 ).

Details follow:

- Problems with PDFs root in the origin of the document. Old documents scanned, heavily annotated, saved as imagebased copies many times, prevent a screen adjuster from yielding usable files. Assessible PDFs require an alternative version be made available in a basic Microsoft Word or a compatible format (Sushil \& Meloncon, 2014).

- Problems withvideos that do not include a transcript or closed captions root in an inability to hear the audio. A transcript and/or closed captions should accompany course-based videos.

For a list of common forms of noncompliant practices see Figure 2 (Table: Accessible and Noncompliant Examples).

Transcripts and closed captions are now a legal obligation for universities that receive federal funding for research supports, because students learn best when information is delivered in both, written and oral modes. (U.S. Department of Education, 2018; Office of Civil Rights, 2018). All enhancements stated help ensure students with disabilities have accommodations for equal access (Solovieva \& Bock, 2014).

\section{3}

\section{Step III}

Practice Exercises. Complete and share with the class.(Dewey's (1938) Element 4: Allow students to incorporate social interactions into the educational experience.)

\section{Part A}

Assignments options:

- Civil Rights Laws and Discrimination 
- Accessibility and Compliance Regulations for E-Learning

- Options for accessibility within Microsoft Office

- Accessible fonts, hyperlinks, alt text, alt tags, images, and colors

- Accessible formats for headings, subheadings, bullet/numbered lists, and table/charts

\section{Part B}

Discussion of content:

1. Students participate in an asynchronous discussion which conveys their comprehension of accessibility.

2. Communication practices for future "real-world" endeavors (e.g., website development, electronic BLOGs, online discussion boards, or written assignments, etc.) are discussed by students.

3. Each student comments on his or her classmates' discussion contributions and topic comprehension.

\section{Part C}

Practical application:

1. An introductory project is assigned which can allow students to demonstrate compliant, accessibility skills.

To illustrate:

a. Each student creates their own introduction, within a web-based, homepage format.

b. Homepages should incorporate a banner and a graphic with a photo/image.

c. Hyperlinks to each student's favorite Internet sites should be included.

d. All document elements are required to have proper color, font, alt text, alt tags, and titled links.

e. A closed-captioned video with a transcript should be attached.

2. To double-check assignments, see Figure 3 (Table: Student Checklist for Course Accessible Contributions).

\section{4}

\section{Step IV}

Instructor Evaluation. Feedback with technique approval. (Dewey's (1938) Element 3. Provide the student with feedback.)Final grades with instructor generated comments:

1. Score each student's ability to implement accessibility guidelines.

2. Approve accessibility skills for future class communication.

3. If needed, require rewrites and/or revisions.

\section{Pilot Study Results}

Within two upper-division, undergraduate courses titled, "Expository Writing for Administration" and "Managerial Communication" offered at, California State University, San Bernardino's Palm Desert Campus (CSUSB-PDC) during the Spring Quarter of 2018, the Four-Step, 360 Degree Accessibility's pilot study was administered. Enrollment totals had a convenient sample of 49 business management students. The first course was fully online with 26 students enrolled, and the second course was hybrid with 23 students enrolled. Five students were of disability status; however, it is not known if their status included visual or auditory impairments?

Since literature on students' development includes moral and cognitive aspects, the undergraduate should be exposed to a multitude of perspectives (Blanchard-Fields, 1989; King \& Kitchener, 1994; Perry, 1981). Syllabus overviews and assignment summaries were implemented with strict adherence to 360-Degree Accessibility. (Review Figures 1-3.) Within each of these class sections, the first week's lesson modules followed the "Four-Step Process Implementation" noted above in Sections: 4, 4.1-4.4. With high assignment scores earned, reviews revealed that comprehension of accessibility processes took place. Eighty-two percent of the class participants scored within the 79-96 percentiles on introductory requirements.

As the academic quarter continued, accessibility practices flaunted nondiscriminatory, course-related, communication protocols. Both class sections required multiple online assignments that were at intervals, posted to Internet sites. The spillover effect was positive. Social awareness and social responsibility were demonstrated. Students felt comfortable with all course-required standards, and many felt they acquired valuable new skill sets. One managerial communication student commented within a platform discussion:

I've taken other online classes and no other professor ever brought disability concepts to my attention. I now check standards and guidelines before I post online communication. I even notice that some sites pay little attention to accessibility practices. I love learning new skills and learning about other people. It is comforting to know that this course has provided a way to learn new skills. Pleased with the pilot, the instructor will continue to implement 360 Degree Accessibility and its processes into upcoming e-learning curriculums for the Academic Year, 2019-20. Future data sets will cover a larger time span and a larger research population. Advanced data will be generated for future consolidation. 


\section{Future Needs and Conclusion}

The greatest impact on accessibility guidelines comes from each institution's policies, instructional practices, and student participants (Foley \& Ferri, 2012).Literature is replete. Change is a "top-down" process. Information expansion can originate within each institution's on-site training. A target would be to raise accessibility and disability awareness; plus, demonstrate practical pedagogies aligned with equal opportunity and reasonable accommodation. Workshops, summer institutes, and new faculty orientations are all training components that could overview; (a) knowledge enhancement (b) communication enrichment, (c) hands-on experience, and (d) accessibility development.

Since faculty members are accountable for how their e-learning structures are developed and presented, future research should probe moral and legal responsibilities of instructors to teach accessible e-learning protocols. Expanded research can document the negative impacts of inaccessible e-learning. To wholly support academic success, colleges and universities should encourage their professors to fill inaccessible e-learning gaps, proactively! Accessibility requirements can be stated upfront, on each class syllabus. Retrofitted processes are documented ineffective (Ellis \& Kent, 2011).

The disabling nature of e-learning course content does not have to be a deliberate disadvantage for students (Foley \&Ferri, 2012). Afford the same e-learning opportunities to all student populations, introduce, teach, and require, basic accessibility guidelines within e-learning classrooms. Course contributions play a large part in the success or failure of every student (Sachs \& Schreuer, 2011).Instructional technology is not inherently accessible (Fichten,Asuncion, Barile,Ferraro, \& Wolforth, 2009).

E-learning (online and hybrid) continues to prosper within higher education and its environments (Allen \& Seaman, 2014); therefore, all e-learning students should also continue to prosper. Student success is an imperative obligation for colleges, universities and their instructional practitioners (Lazer\& Jaeger, 2011). Following the Four-Step Process to Achieve 360-Degree Accessibility presents equal education regardless of disability while, processes are compatible with many types of assisted technologies.

In document summary, accessibility practices enhance social awareness and social responsibility for all class participants. This paper seeks to bring a current issue forward; provide an improvement method; and teach reasonable accommodation via compliant, accessibility guidelines. The content in no way insinuates that decisions made by any college, university, or instructional practitioner regarding accessibility are inadequate. A "one size fits all" approach isn't valid.

\section{Flowchart and Tables}

\section{Figure 1}

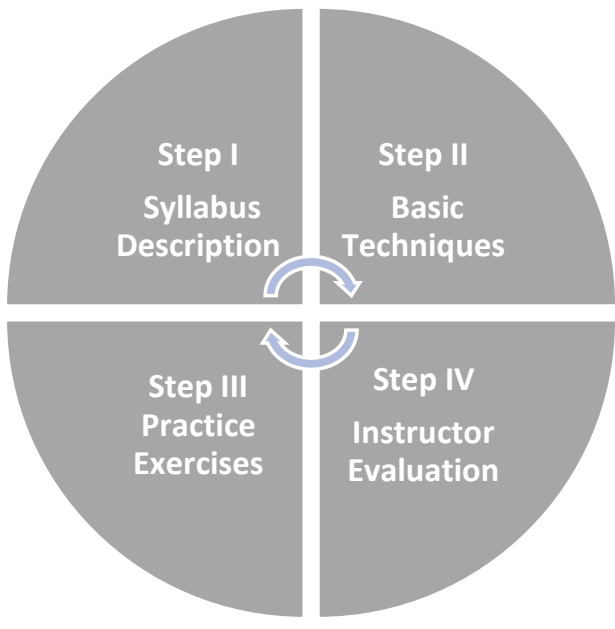

Flowchart: Four-Step, 360-Degree Accessibility

Step I. Syllabus Description.

Require accessibility standards.

Step II. Basic Techniques.

What is and what is not, accessible.

Step III. Practice Exercises.

Complete and share with class.

Step IV. Instructor Evaluation.

Feedback with technique approval.

Figure 2 
Table: Accessible and Noncompliant Examples

\begin{tabular}{lll}
\hline \multicolumn{1}{c}{ Accessible } & Noncompliant \\
\hline Links & Online Programs at CSUSB & $\begin{array}{l}\text { Online Programs at CSUSB } \\
\text { https://www.csusb.edu/academics/online- } \\
\text { programs-csusb }\end{array}$ \\
$\begin{array}{l}\text { [URL link is: } \\
\text { https://www.csusb.edu/academics/online-programs- } \\
\text { csusb ] }\end{array}$ & $\begin{array}{l}\text { Light colors on white do not work } \\
\text { Text }\end{array}$ & $\begin{array}{l}\text { This is not the same font } \\
\text { This is the same font! }\end{array}$ \\
& $\begin{array}{l}\text { Do not shout! } \\
\text { Use underlines for hyperlinks, only. }\end{array}$ & AVOID ALL CAPS \\
Arial, Geneva, Helvetica, Tahoma \& Veranda & Hyperlinks are Underlined. \\
Avoid bright colors and red. & Sans typeface does not have "serifs" \\
\hline
\end{tabular}

(VVC, 2018).

Figure 3

Table: Student Checklist for Course Accessible Contributions

\begin{tabular}{ll}
\hline Links & Uses a text description for all web links. \\
\hline \multirow{3}{*}{ Text } & Provides when appropriate, the notation [URL link is: http://...] \\
& Exercises dark fonts on light backgrounds orlight texts on dark backgrounds. \\
& Maintains the same font throughout a document and/or electronic course contribution. \\
& Uses Sans Serif fonts that areconsistent in sizes and in colors. \\
& Avoids underling words to avoid confusion with navigation links \\
& Eludes the overuse of all CAPS, bold or italics. \\
Images & Eliminates bright colors and red; substitutes red with dark brown or maroon. \\
& Provides clear images optimized for efficient loading and viewing. \\
& Avoids animated and/or blinking images. \\
Audio & Uses alt text for all images with clear text descriptions. \\
& Provides clear quality with a written transcript. \\
Video & Maintains platform length capabilities. \\
Misc. & Delivers clearquality with closed captioning and/or a written transcript. \\
& Implements graphs and charts with a full text equivalent. \\
& Provides PDF's with text that can be copied/pasted. \\
\hline
\end{tabular}

(Victor Valley College [VVC] 2018).

\section{References}

Allen, I. \& Seaman, J. (2014). Grade Change: Tracking Online Learning in the United States. Wellesley MA: Babson College/Sloan.

Ames, C. \& Archer, J. (1988). Achievement goals in the classroom: Students' learning strategies and motivation processes.Journal of Educational Psychology, 80(3), 260-267.

Bakia, M., Shear, L., Toyama, Y., \& Lasseter, A. (2012). Understanding the Implications of Online Learning for Educational Productivity. Washington, DC: U.S. Department of Education, Office of Educational Technology.

Blackboard:(n.d.). Integrate Blackboard Collaborative with your LMS.[Online] Available:

https://www.blackboard.com/online-collaborative-learning/learning-management-system-integration.html(September 3, 2018).

Blanchard-Fields, F. (1989). Postformal reasoning in socioemotional context. In M. Commons (Ed). Adult Development: Vol.1. Comparisons and applications of developmental models. (pp.73-94). New York: Peager.

Burgstahler, S., Corrigan, B. \& McCarter, J. (2004). Making Distance Learning Courses Accessible to Students and Instructors with Disabilities: A Case Study. Internet and Higher Education, 7(3), 233-246. [Online] Available: https://www.learntechlib.org/p/102646/ (November 27, 2018).

Carlzon, J. (1987). Moments of Truth. Cambridge, Ballinger, MA. [Online] Available:https://journals.sagepub.com/doi/abs/10.1177/017084068800900314(July 30, 2018).

Crawford, C., Barker, J., Seyam, A., (2014). The promising Role Of Hybrid Learning In Community College: Looking Towards The Future. Contemporary Issues In Education Research, 7(3). 
Dewey, J. (1938). Experience \& Education. New York, NY: Macmillan. [Online]

Available:https://archive.org/details/ExperienceAndEducation(July 1, 2018).

Educause Review: ADA Compliance for Online Course Design. [Online] Available: https://er.educause.edu/articles/2017/1/ada-compliance-for-online-course-design(October 10, 2018).

Ellis, K. \&Kent, M. (2011).(Physical) Disability Is a Form of Social Oppression? Disability and New Media (pp.81-93). New York, NY: Routledge

Fichten, C. S., Asuncion, J. V., Barile, M., Ferraro, V., \&Wolforth, J. (2009). Accessibility of e-learning and ICT for students with visual impairments in postsecondary education. Journal of Visual Impairment \& Blindness, 103(9), 543-557.

Finkelstein, Victor (1980). Attitudes and disabled people: issues for discussion. International Exchange of Information in Rehabilitation, New York, N.Y.[Online] Available: https://disability-studies.leeds.ac.uk/wpcontent/uploads/sites/40/library/finkelstein-attitudes.pdf(September 10, 2018).

Foley, A., \&Ferri, B (2012).Technology for people, not disabilities: ensuring access and inclusion [Online] Available: https://onlinelibrary.wiley.com/doi/abs/10.1111/j.1471-3802.2011.01230.x(August 6, 2018).

King, P.M. \&Kitchener, K.S. (1994). Developing reflective judgement: Understanding and promoting intellectual growth and critical thinking in adolescents and adults. San Francisco: Jossey-Bass.

Gee, J.P. (2008). Learning and games. In K. Salem (Ed), The ecology of games: Connecting youth, games, and learning (pp.21-40). Cambridge: The MIT Press.

Graham, C. R., Allen, S., \&Ure, D. 2005. Benefits and Challenges of Blended Learning Environments. In KhosrowPour, M. (Ed.), Encyclopedia of Information Science and Technology (pp. 253-259). Hershey, Pennsylvania: Idea Group.ResearchGate. [Online] Available:

https://www.researchgate.net/publication/255641218/download(August 1, 2018).

Ingeno, L. (2013). Online Accessibility a Faculty Duty Inside Higher Education. [Online] Available: https://www.insidehighered.com/news/2013/06/24/faculty-responsible-making-online-materials-accessibledisabled-students(August 1, 2018).

Lazer, J. and Jaeger, P.T. (2011). "Reducing barriers to online access for people with disabilities, "Issues in Science and Technology, volume 17, number 2, pp.68-82, [Online] Available:

http://issues.org/27-2/lazar/accessed(July 26, 2018).

May, A. L., \& Stone, C. A. (2010). Stereotypes of individuals with learning disabilities: views of college students with and without learning disabilities. Journal of Learning Disabilities, 43(6), 483-499.

doi: $10.1177 / 0022219409355483$.

National Education Association (NEA), (2018). NEA Positions on Technology and Education. [Online] Available: http://www.nea.org/home/58795.htm(July 1, 2018).

National Institutes of Health (NIH), U.S. Department of Health and Human Services, (2018). What are some types of assistive devices \& how are they used? [Online] Available:

https://www.nichd.nih.gov/health/topics/rehabtech/conditioninfo/device (July 2, 2018).

Perry, W.G. (1981). Cognitive and ethical growth: The making of meaning. In A. Chickering (Ed.), The modern American college (pp.76-116). San Francisco: Jossey-Bass.

Picard, D. (2014). Center for Teaching: Teaching Students with Disabilities. Vanderbilt University.[Online] Available: https://wp0.vanderbilt.edu/cft/guides-sub-pages/disabilities/ (November 1, 2018).

Roberts, J. B., Crittenden, L. A., \& Crittenden, J. C. (2011). Students with disabilities and online learning: A crossinstitutional study of perceived satisfaction with accessibility compliances and services. Internet and Higher Education, 14(4), 242-250.

Sachs, D., \&Schreur, N. (2011). Inclusion of students with disabilities in higher education: Performance and participation in student's experiences. Disability Studies Quarterly 31(2). doi: 10.18061/dsq.v31i2.1593 Sanford

Shea, P. (2006). A study of students' sense of learning community in online environments. Journal of Asynchronous Learning Networks, 10(1), 35-44.

Solovieva, T. I., \& Bock, J. M., (2014). Monitoring for Accessibility and University Websites: Meeting the Needs of People with Disabilities. Journal of Postsecondary Education and Disability, v27 n2 p113-127 Sum 2014(EJ1040525).

Sushil K. O. \&Meloncon, L., (2014).Paying Attention to Accessibility When Designing Online Courses in Technical and Professional Communication. Journal of Business and Technical Communication. 28(3) 271-300. DOI: $10.1177 / 1050651914524780$ jbtc.sagepub.com.

Thomas, S. (2000). College Students and Disability Law. The Journal of Special Education, 33(4), 248-257. [Online] Available: https://doi.org/10.1177/002246690003300408 (July 2, 2018). 
U.S. Department of Education, (2008). Laws \& Guidance/Civil Rights: Disability Discrimination. [Online] Available: https://www2.ed.gov/policy/rights/guid/ocr/disability.html (July 10, 2018).

U.S. Department of Education, Office of Civil Rights (OCR), (2018). Protecting Students With Disabilities: Frequently Asked Questions About Section 504 and the Education of Children with Disabilities. [Online] Available: https://www2.ed.gov/about/offices/list/ocr/504faq.html accessed 25 July 2018(July 8, 2018).

U.S. Department of Education and U.S. Department of Justice, (2010). Electronic book reader dear colleague letter: Questions and Answers about the law, the technology, and the population affected. [Online] Available: http://www.tamut.edu/training/PDFs/ADA\%20Presentation\%20Materials.pdf(July 4, 2018).

University of Washington (UW), (2018). Accessible Technology: Resolution Agreements and Lawsuits. [Online] Available: agreements/ (July 20, 2018).

Victor Valley Community College. (2018, June 6). Re: Online Course Reviews. Message posted to Institutional SharePoint, archived [Online] Available:

http://www.vvc.edu/offices/oie/program-review_home-old.shtml(July 20, 2018).

Watson, J. F. (2008). Blended learning: The convergence of online learning and face-to-face education. [Online] Available:http://www.inacol.org/resources/promisingpractices/NACOL_PPBlendedLearning-lr.pdf(September 1, 2018). 